\title{
Associations between the Home Physical Environment and Children's Home-Based Physical Activity and Sitting
}

\author{
Michael P. Sheldrick ${ }^{1, *}\left(\mathbb{D}\right.$, Clover Maitland ${ }^{2,3}$, Kelly A. Mackintosh ${ }^{1} \oplus$, Michael Rosenberg ${ }^{3}$, \\ Lucy J. Griffiths ${ }^{4}$, Richard Fry ${ }^{4}$ and Gareth Stratton ${ }^{1}$ (I) \\ 1 Research Centre in Applied Sports, Technology, Exercise and Medicine (A-STEM), Swansea University, \\ Swansea SA1 8EN, UK; k.mackintosh@swansea.ac.uk (K.A.M.); g.stratton@swansea.ac.uk (G.S.) \\ 2 Centre for Urban Research, RMIT University, Melbourne, Victoria 3000, Australia; \\ clover.maitland@rmit.edu.au \\ 3 School of Human Sciences (Exercise and Sport Science), University of Western Australia, \\ Perth 6009, Australia; michael.rosenberg@uwa.edu.au \\ 4 Health Data Research UK, Wales and Northern Ireland, Swansea University Medical School, \\ Swansea SA2 8PP, UK; lucy.griffiths@swansea.ac.uk (L.J.G.); r.j.fry@swansea.ac.uk (R.F.) \\ * Correspondence: 708824@swansea.ac.uk; Tel.: +44-7749-767373
}

Received: 5 September 2019; Accepted: 24 October 2019; Published: 29 October 2019

\begin{abstract}
It is important to understand the correlates of children's physical activity (PA) and sitting at home, where children spend significant time. The home social environment has an important influence; however, much less is known about the home physical environment. Therefore, the study aimed to assess relationships between the physical environment and children's sitting and PA at home. In total, 235 child-parent dyads were included in the analyses. Children spent $67 \%$ of their time at home sitting. Linear regression analyses examined associations between physical home environmental factors obtained via an audit and children's (55\% girl, $10.2 \pm 0.7$ ) objective PA and sitting at home. Following adjustment for socio-demographics and social environmental factors, an open plan living area (OPLA), musical instrument accessibility and availability, and perceived house size were negatively and positively associated, whereas media equipment accessibility and availability was positively and negatively associated with sitting and standing, respectively. Additionally, an OPLA was positively associated with total and moderate-to-vigorous PA. Furthermore, sitting breaks were positively associated with objective garden size and negatively associated with digital TV. The physical home environment may have an important influence on children's sitting, standing and PA at home; therefore, interventions that target this environment are needed.
\end{abstract}

Keywords: house; moderate-to-vigorous physical activity; families; youth; objective; standing; screen-time

\section{Introduction}

The importance of physical activity (PA) for children's physiological and psychological health has been well documented [1], yet few meet current moderate-to-vigorous physical activity (MVPA) recommendations [2]. Children also spend most of their discretionary time in sedentary behaviours (7-8 h daily) [3], defined as 'any waking activity, in a sitting, lying or reclining posture with an energy-expenditure below 1.5 metabolic equivalents (METs)' [4]. Screen-time is the most prevalent sedentary behaviour, and has been associated with poor health outcomes [5]. However, the relationship between overall sedentary time and health in children is less clear [5]. Nonetheless, there is strong evidence for an adverse association between excessive levels and mortality in adults [6]. Recently, 
breaks from prolonged sitting have been beneficially associated with markers of body composition and metabolic health in adults [7]. Given the harmful consequences in adults and that children's sedentary time appears to track into adulthood [8], high levels in children are a public health concern. Therefore, it is important to develop interventions to increase children's PA and reduce their sedentary time.

Investigating the correlates of PA and sedentary time is essential for informing effective evidence-based interventions [9]. The social ecological model is often used to guide the understanding of children's PA and sedentary time, recognising the important influence of the environment [10]. This model suggests that behavioural correlates are domain-specific, whereby behaviours are most likely influenced by the environment in which they occur $[10,11]$. Outside of school hours, children have been shown to spend significant time at home $[12,13]$. Indeed, there is also evidence indicating that a large proportion of children's sedentary time and PA occurs at home [14-16]. Specifically, Tandon et al. [16] found that 48 and $42 \%$ of children's overall sedentary time and MVPA, respectively, was accumulated at home. The home environment, therefore, may be influential in affecting children's PA and sedentary behaviours.

There is a plethora of research demonstrating the importance of the home social environment on children's PA and sedentary time $[17,18]$. However, much less is known about physical environmental factors at home. Media equipment in the home and bedroom has consistently been positively associated with screen-time, but not overall sedentary time $[17,18]$. Additionally, there is some evidence that PA equipment is positively associated with PA $[16,19]$ and inversely related to sedentary time $[16,17]$. Furthermore, whilst PA at home is most likely to occur outdoors [20], whether greater garden space facilitates PA remains unclear, with equivocal findings [21,22]. Even though there is an emerging evidence base, findings have been inconsistent, and research has been limited by the use of self-report instruments to measure the home and through assessing PA and sedentary time across the entire day [17]. Given behaviours are most likely influenced by the setting in which they occur [10], investigating sedentary time and PA at home will enable more precise identification of correlates. The use of objective measures such as audits and geographic information system (GIS) software to assess the home will also improve measurement accuracy. Additionally, greater media equipment accessibility has been shown to be associated with increased screen-time [19]; however, most studies have only assessed equipment availability.

When at home, children spend most of their time indoors [12,13]. This is of concern, because this is where children are most likely to be sedentary [20]. The indoor space may also be relevant for PA, with an ecological momentary assessment study showing that 30\% of children's aged 9-13 years leisure time PA occurred at home indoors [15]. Yet, few studies have explored influences on sedentary time and PA within the home indoor physical environment, outside of equipment [17]. A qualitative study identified several previously unexplored indoor physical environmental factors as potential influences on children's sedentary time and PA at home, including multiple indoor living areas designated for screen-time, the presence of an open plan living area, the availability and layout of indoor space, as well as furniture within the home [23]. Additionally, new electronic media technologies such as online $\mathrm{TV} /$ movie streaming services may also be relevant, with just over 11 million people in the UK now being subscribed to one, as TV viewing habits shift online [24]. Moreover, playing musical instruments is an activity that commonly occurs at home [25], which can be done while sitting or standing [26]. Furthermore, houses with more than one floor may have a favourable effect on PA via increased stair climbing [27,28]. Exploration of the role of the factors cited by Maitland et al. [23], as well as musical instruments, movie/TV streaming services and the number of floors in influencing children's sedentary time and PA is needed.

The aim of this study was to investigate the relationship between characteristics of the physical home environment and children's home-based sitting, PA, standing and sitting breaks. 


\section{Materials and Methods}

\subsection{Study Design}

The HomeSPACE study is a cross-sectional observational study investigating the influence of the home environment on children's PA levels and sedentary time. Between November 2017 and July 2018, 235 children aged 9-12 years and their parents $(n=228)$ (response rate 26\%) were recruited through primary schools from four of the largest conurbations in South Wales, Swansea $(n=174)$, Bridgend $(n=37)$, Cardiff $(n=16)$ and Newport $(n=8)$. A target sample size of 235 was set based on a reliable formula [29], while accounting for the possibility of missing data.

\subsection{Recruitment}

Primary schools $(n=23)$ were invited to participate. Eleven schools (response rate $48 \%$ ) consented and 890 children aged 9-11 years were provided with information about the study. To be eligible, children had to be aged 9-12 years and without a physical disability. A chance to win a family pass for an outdoor adventure centre and the child's sitting and PA results were offered as incentives. Informed consent and child assent were provided. The Swansea University ethics committee granted ethical approval for the study.

\subsection{Home Physical Environment}

HomeSPACE-II, an updated version of the HomeSPACE-I [30] and the Physical Activity and Media Inventory [31], was administered to the parents. The audit assessed physical home environmental factors hypothesised to influence children's home-based PA and sedentary behaviours [23]. Parents were asked to walk around their house and garden and complete the items for each room/area. Briefly, the audit allowed the presence, amount and accessibility of 41 media (e.g., TV, computer, etc.), musical (e.g., drums, piano, etc.), PA (e.g., balls, trampoline, etc.) and seated furniture (e.g., sofa, desk etc.) items to be recorded for up to 22 room/areas (14 indoor and eight outdoor). Accessibility of each item was rated on a scale of A-D [31]. The response options were; A: put away and difficult to get to; B: put away and easy to get to; $C$ : in plain view and difficult to get to; D: in plain view and easy to get to. There were questions relating to home features (house size, garden size, type of house, number of floors) and electronic media (smartphones, TV service, movie/TV streaming service). In addition, there were questions referring to the space to play inside the house, and in the back and front garden [30]. The audit data were reduced to several independent variables. Three dichotomous variables were generated to reflect the presence of: (1) an open plan living area; (2) a TV in the primary child's bedroom; (3) a detached house. Yes and no responses were coded as 1 or 0 , respectively. The number of living areas in the home with a TV was also calculated. In addition, summary scores that accounted for the accessibility and availability of PA equipment, seated furniture, overall media equipment, media equipment in the child's bedroom and musical instruments were created by multiplying each item by its accessibility rating $(\mathrm{A}=1, \mathrm{~B}=2, \mathrm{C}=3, \mathrm{D}=4)$. A higher score indicates a greater overall "presence" of that type of item in the home. For descriptive purposes, we also calculated the total number of each type of item and the number of rooms/areas. Active video game systems (e.g., Wii Fit, Xbox Kinect, PlayStation move) were coded as PA equipment. Instruments were checked for missing data and for clarity, and followed up with families when needed.

\subsection{Home Log Diary}

Parents were given a diary to record when the child was at home each day for seven days, to allow for the calculation of home-based behaviours. Instructions were provided, where "Home" was defined as a single location, including the house, garden, driveway and verge of the home where the child spends most of their time (i.e., excluding homes of other parents). To minimise missing data, children completed the diary when parents were unable to and incomplete diaries were followed up with families. 


\subsection{Objectively Measured Home-Based Physical Activity and Postural Behaviours}

Children wore the ActiGraph GT9X (ActiGraph, Pensacola, FL, USA) and the activPAL3 micro (PAL Technologies, Glasgow, UK), which measured total physical activity (TPA) and MVPA as well as postural behaviours (i.e., sitting, standing and sitting breaks), respectively, for seven consecutive days. A siting break was defined as a transition from sitting to standing/stepping [4]. Both were fitted at school, to ensure correct attachment and to provide instructions on how to reattach them. Participants were asked only to remove the monitors for swimming. Parents were also required to record sleep and wake times, device removals and any illness days.

The activPAL has demonstrated excellent validity in children [32], and was placed in a waterproof nitrile sleeve and secured on the midline of the upper right thigh using a hypoallergenic dressing (3M Tegerderm or Hypafix Transparent). Supplementary dressings, sleeves and instructions on correct reattachment were provided. ActivPAL data were downloaded using the manufacturer software (V8.10.8.32, PAL technologies, Glasgow, UK), which generated Event.csv files for each device. These files were processed in ProcessingPAL-V1.1 (Leicester, UK) using a validated algorithm to identify waking hours, extended non-wear periods ( $\geq 5 \mathrm{~h}$ ) and invalid data [33]. Following processing, files were visually checked for plausibility of sleep/non-wear classification using heatmaps. If sleep and wake times looked unfeasible, the diaries were referred to for verification and when times differed by $\geq 2 \mathrm{~h}$, the diary times were utilised [34]. Additionally, removals noted in the diary were inspected against heatmaps and the events window in the PAL analysis software (V8.10.8.32, PAL technologies, Glasgow, UK), and removed using the software if deemed plausible. Bouts were considered as "non-wear/sleep", if $\geq 50 \%$ of it was within the period reported in the diary [35]. To minimise known errors with self-reported diary data, based on inspections of the data and previously used methods [36], we considered sitting/lying or standing bouts lasting $\geq 3 \mathrm{~h}$ without transitions as non-wear time.

Children wore the ActiGraph GT9X on their non-dominant wrist [37], to improve compliance [38]. Wrist-worn accelerometers have demonstrated good validity in comparison to hip-worn accelerometers [39]. The data was collected at a $30 \mathrm{~Hz}$ sampling rate [40] and summed over 5-sec epochs. ActiGraph (ActiLife V6.13.3) software was used to initialise, download and process files. Chandler wrist-based cut-points [41], applied to the vector-magnitude, were used to categorise MVPA ( $\geq 818$ counts/5-secs) and TPA ( $\geq 162$ counts/5-secs). Non-wear time, defined as $\geq 90$ consecutive minutes of zero counts [42], was removed using the software.

Periods when children were at home were uploaded into both the ActiGraph and Processing PAL software and matched with time-stamped data, allowing home-based PA and postural behaviours to be generated, respectively. Days were considered valid, when the device was worn for $\geq 75 \%$ of the time at home [43]. In accordance with previous research [44], children with completed home diaries, and at least one valid day with $\geq 3 \mathrm{~h}$ of wear time at home were included in the analyses. Reported illness days were also excluded from the analyses. ActivPAL and ActiGraph data in minutes, were divided by wear time at home and multiplied by 60 to create the dependent variables conveyed as averages/h [45].

\subsection{Children Personal Information and Anthropometric Measures}

Anthropometric measurements were taken at the children's respective schools. Stature and body mass were measured to the nearest $0.001 \mathrm{~m}$ and $0.1 \mathrm{~kg}$, using a portable stadiometer (Seca 213, Hamburg, Germany) and electronic weighing scales (Seca 876, Hamburg, Germany), respectively, using standard anthropometric techniques [46]. Body mass index (BMI), and subsequently BMI z-scores, were derived using the WHO (World Health Organization) growth reference standard [47].

\subsection{Objectively Measured House and Garden Size}

Objective house and garden size for each postcode were measured using GIS techniques, AddressBase Premium (ABP) [48] and Ordnance Survey MasterMap (OSMM) [49]. For residences 
(min 4-max 82), we extracted building footprints from OSMM and filtered out non-residential buildings, defined by ABP. The process was repeated to determine garden size for residences ( $\min 2-\max 82$ ), defined in OSMM Greenspace dataset [50]. To estimate house size, a median of the extracted building footprints was calculated and multiplied by the number of floors in each house. A median garden size was also calculated for each home in the postcode.

\subsection{Additional Measures}

Parents reported their age, gender, whether they own or rent their home, educational status (Some secondary school/Completed secondary school/Trade qualifications or apprenticeship/Diploma or certificate/University degree or higher), the pre-tax annual household income, postcode and the number of children at home. Season of measurement covered four categories: Winter (December-February), Spring (March-May), Summer (June-August) and Autumn (September-November). Due to missing data on income and educational status, Welsh Index of Multiple Deprivation (WIMD) scores, derived from postcodes, were used as an indicator of socioeconomic status (SES). The WIMD scores, consider eight domains of deprivation; employment; health; income; housing; community safety; access to services; education; the environment [51]. Small areas in Wales are ranked 1-1909, where 1 is the most deprived and 1909 is the least deprived. For descriptive purposes, tertiles of SES were generated based on WIMD scores; low (1-636), medium (636-1272) and high (1272-1909). Daylength for the participants' respective cities during each monitoring day was obtained from a valid and reliable online resource [52]. Family preferences and priorities for activity within the home [30], as well as parental media rules [53] were collected via validated questions. Social and individual factors have been known to influence children's sedentary and activity behaviours at home [23]; therefore, they could play an important role in associations with such behaviours and the home environment. To identify the confounding factors, the coefficients were computed from the statistical models prior to and following adjusting for each variable. Variables with the greatest influence on the coefficients on average were controlled for in the models [54]. These were parent-reported child and parent activity preferences at home, parent perceptions of the importance of active play at home for their child, and whether parents enforce a maximum $\mathrm{h} /$ day of screen-time rule.

\subsection{Statistical Analysis}

Consent and assent as well as activPAL, ActiGraph, physical and social environment data were received for $235(100 \%), 207(88 \%), 214(91 \%), 213(91 \%)$ and $207(88 \%)$ children, respectively. Statistical analyses were conducted using SPSS (IBM SPSS Statistics Inc., Chicago, IL, USA; Version 25), where significance was set at $\leq 0.05$. Influential outliers were replaced with the largest or second smallest value in observations [55] for overall media equipment $(n=1)$ and bedroom media equipment $(n=1)$ summary scores. The unadjusted associations between each of the physical environment variables and the five home-based outcomes (min/h spent sitting, standing, in TPA and MVPA and the number of sitting breaks/h) were examined using linear regression (Model 1). Model 2 adjusted for home ownership, raw WIMD scores, season of measurement, daylength and the number of siblings at home, as well as the BMI, age and sex of the child. Model 3 further adjusted for social environmental factors associated with children's PA and sedentary time. A final model (Model 4) was run for each of the five outcomes, including all the significant variables $(p \leq 0.10)$ [56] from model 3 and adjustment variables to determine independent associations between physical environment factors and the child home-based outcomes. Paired t-tests revealed that the outcomes differed between weekday and weekend days. However, separate analyses had little effect on findings; thus, weekday and weekend days were combined. 


\section{Results}

Descriptive statistics are provided in Table 1. The participating children had a mean age of $10.2 \pm 0.7$, and $55 \%$ were girls. Children spent $40.3 \pm 5.9$ min sitting $(67 \%), 12.3 \pm 4.2$ min standing, $21.6 \pm 4.7 \mathrm{~min}$ in TPA, $6.7 \pm 2.3 \mathrm{~min}$ in MVPA, and had $7.0 \pm 1.9$ sitting breaks per hour at home. Most parents who completed the audit and questions were female (83\%), owned their home (86\%), held a university degree (54\%) and lived in the highest SES location (59\%). Homes (i.e., the overall plot, including house and outdoor space) were perceived to have medium houses $(60 \%)$ which were not detached $(64 \%)$ and large gardens (46\%), they mostly had two floors $(77 \%)$, and had on average four occupants, including two children. Most parents enforced a maximum $\mathrm{h} /$ day of screen-time rule $(69 \%)$ and on average thought it was 'important' for their child to engage in active play at home, their child and themselves enjoyed sedentary and PA activities at home 'about equal' and 'strongly agreed' that their child had enough space to play inside the house and in the back garden. Homes had $11.5 \pm 2.1$ rooms/areas, $57 \%$ had an open plan living area and $52 \%$ of the children had a TV in their bedroom. Homes averaged $27.7 \pm 18.3$ PA equipment items, $19.6 \pm 8.0$ seated furniture items, $2.0 \pm 2.1$ musical instruments, $11.6 \pm 4.7$ media equipment items overall and $1.9 \pm 1.7$ in the primary child's bedroom. Lastly, homes tended to have digital TV ( $82 \%)$, access to a movie/TV streaming service $(77 \%)$ and 3-4 smartphones.

Table 1. Participant characteristics and descriptive statistics.

\begin{tabular}{|c|c|c|}
\hline Variable & Mean (SD) or \% & $n$ \\
\hline \multicolumn{3}{|l|}{ Parental Characteristics } \\
\hline Parent age & $41.5(5.7)$ & 211 \\
\hline Parent gender (\% Female) & $83 \%$ & 213 \\
\hline Parent activity preferences at home ${ }^{2}$ & $3.4(0.7)$ & 211 \\
\hline Parent perceived importance of engaging in active play at home for child ${ }^{3}$ & $4.0(0.8)$ & 207 \\
\hline Maximum h/day of screen-time rule (\% yes) & $69 \%$ & 206 \\
\hline Parental education ** & & 207 \\
\hline Secondary school or lower & $12 \%$ & \\
\hline Diploma/Trade & $34 \%$ & \\
\hline University degree or higher & $54 \%$ & \\
\hline \multicolumn{3}{|l|}{ Child Characteristics } \\
\hline Child age & $10.2(0.7)$ & 233 \\
\hline Child sex (\% Girl) & $55 \%$ & 235 \\
\hline Child BMI-z-score & $0.6(1.1)$ & 233 \\
\hline Child activity preferences at home ${ }^{2}$ & $3.3(0.8)$ & 207 \\
\hline \multicolumn{3}{|l|}{ Family Characteristics } \\
\hline Number of siblings & $1.2(0.9)$ & 213 \\
\hline Number of people at home & $4.1(1.1)$ & 213 \\
\hline Home ownership & & 213 \\
\hline Rent & $14 \%$ & \\
\hline Own & $86 \%$ & \\
\hline SES (based on WIMD scores) ${ }^{* *}$ & & 220 \\
\hline Low & $14 \%$ & \\
\hline Medium & $27 \%$ & \\
\hline High & $59 \%$ & \\
\hline
\end{tabular}


Table 1. Cont.

\begin{tabular}{|c|c|c|}
\hline Variable & Mean (SD) or \% & $n$ \\
\hline \multicolumn{3}{|c|}{ Home Characteristics and Features } \\
\hline Perceived house size & & 213 \\
\hline Small & $8 \%$ & \\
\hline Medium & $60 \%$ & \\
\hline Large & $32 \%$ & \\
\hline Objectively measured house size $\left(\mathrm{m}^{2}\right)$ & $145.0(52.1)$ & 207 \\
\hline Perceived garden size & & 213 \\
\hline No garden & $1 \%$ & \\
\hline Small & $15 \%$ & \\
\hline Medium & $38 \%$ & \\
\hline Large & $46 \%$ & \\
\hline Objectively measured garden size $\left(\mathrm{m}^{2}\right)$ & $269.0(166.7)$ & 214 \\
\hline Type of house & & 213 \\
\hline Detached & $36 \%$ & \\
\hline Not detached (semi-detached, terrace, bungalow, flat) & $64 \%$ & \\
\hline Number of floors & & 213 \\
\hline 1 & $4 \%$ & \\
\hline 2 & $77 \%$ & \\
\hline$>2$ & $19 \%$ & \\
\hline Space to play & & 211 \\
\hline Inside the house ${ }^{1}$ & $3.6(0.7)$ & \\
\hline Back garden $^{1}$ & $3.6(0.7)$ & \\
\hline Front garden ${ }^{1}$ & $2.6(1.2)$ & \\
\hline \multicolumn{3}{|c|}{ Audit Variables } \\
\hline Total number of Rooms/Areas ** & $11.5(2.1)$ & 210 \\
\hline Presence of a TV in the child's bedroom (\% yes) & $52 \%$ & 212 \\
\hline Number of living areas with a TV at home & $1.5(0.6)$ & 210 \\
\hline Presence of an open plan living area (\% yes) & $57 \%$ & 211 \\
\hline \multicolumn{3}{|l|}{ Equipment Variables: } \\
\hline Number of PA equipment items** & $27.7(18.3)$ & 210 \\
\hline PA equipment accessibility and availability score & $86.7(63.1)$ & 209 \\
\hline Number of seated furniture items $* *$ & $19.6(8.0)$ & 210 \\
\hline Seated furniture accessibility and availability score & $76.5(31.2)$ & 209 \\
\hline Number of media equipment items ** & $11.6(4.7)$ & 210 \\
\hline Media equipment accessibility and availability score & $44.2(18.2)$ & 209 \\
\hline Number of bedroom media equipment items ${ }^{* *}$ & $1.9(1.7)$ & 212 \\
\hline Bedroom media equipment accessibility and availability score & $6.9(6.3)$ & 210 \\
\hline Number of musical instrument items ${ }^{* *}$ & $2.0(2.1)$ & 210 \\
\hline Musical instrument accessibility and availability score & $7.2(7.5)$ & 209 \\
\hline \multicolumn{3}{|c|}{ Electronic Media Equipment } \\
\hline TV service & & 213 \\
\hline Digital (e.g., SKY, BT etc.) & $82 \%$ & \\
\hline Freeview or other & $18 \%$ & \\
\hline Movie/TV streaming (e.g., Netflix, Amazon TV etc.) [\% yes] & $77 \%$ & 213 \\
\hline Number of smartphones (mode) & $3-4$ & 213 \\
\hline \multicolumn{3}{|c|}{ Outcome Variables } \\
\hline Home-based activPAL outcomes & & 207 \\
\hline Full days of activPAL wear at home & $5.3(1.1)$ & \\
\hline $\mathrm{h} /$ full day of activPAL wear at home & $5.8(1.6)$ & \\
\hline Min/h spent sitting, $\%$ of time at home* & $40.3(5.9), 67 \%$ & \\
\hline Min $/ \mathrm{h}$ spent standing, $\%$ of time at home* & $12.3(4.2), 21 \%$ & \\
\hline Min/h spent stepping, $\%$ of time at home ${ }^{* *}$ & $7.5(2.8), 12 \%$ & \\
\hline Number of sitting breaks/h & $7.0(1.9)$ & \\
\hline Home-based ActiGraph outcomes & & 214 \\
\hline Full days of ActiGraph wear at home & $5.5(0.9)$ & \\
\hline $\mathrm{h} /$ full day of ActiGraph wear at home & $5.8(1.6)$ & \\
\hline Min/h spent in MVPA, $\%$ of time at home & $6.7(2.3), 11 \%$ & \\
\hline $\mathrm{Min} / \mathrm{h}$ spent in TPA, $\%$ of time at home & $21.6(4.7), 36 \%$ & \\
\hline
\end{tabular}

${ }_{1}^{1} 1=$ strongly disagree; $5=$ strongly agree ${ }^{2} 1=$ almost always-sedentary; $5=$ almost always-PA; ${ }^{3} 1=$ unimportant; $5=$ very important; $* \%=$ proportion of time at home; ${ }^{* *}$ Displayed for descriptive purposes only. 


\subsection{Associations between Physical Home Factors and Home-Based Sitting}

When all the confounding factors were controlled for, home-based sitting was negatively associated with a detached house $(-2 \mathrm{~min} / \mathrm{h}, p=0.03)$, an open plan living area $(-2 \mathrm{~min} / \mathrm{h}, p=0.01)$, perceived house size $(-2 \mathrm{~min} / \mathrm{h}, p=0.01)$ and musical instruments, and positively associated with the presence of a TV in the child's bedroom (+2 $\mathrm{min} / \mathrm{h}, p=0.03)$, bedroom media and overall media equipment (Table 2, Model 3). Children spent one additional $\mathrm{min} / \mathrm{h}$ sitting at home for every 13 media equipment points $(p<0.01)$ and seven bedroom media equipment points $(p=0.03)$, and one min/h less for every six musical instrument points $(p<0.01)$. In the final model, negative associations with house size $(-2 \mathrm{~min} / \mathrm{h}, p=0.02)$, an open plan living area $(-3 \mathrm{~min} / \mathrm{h}, p<0.01)$, musical instruments and the positive association with media equipment remained (Table 2, Model 4). Children spent one additional min/h sitting at home for every 13 media equipment points $(p<0.01)$ and one $\mathrm{min} / \mathrm{h}$ less for every seven musical instrument points $(p=0.01)$.

\subsection{Associations between Physical Home Factors and Home-Based Standing}

After adjusting for all confounding factors, a detached house $(+2 \mathrm{~min} / \mathrm{h}, p<0.01)$, perceived house size ( $+1 \mathrm{~min} / \mathrm{h}, p=0.02)$, an open plan living area ( $+2 \mathrm{~min} / \mathrm{h}, p=0.01)$ and musical instruments were positively associated, whereas media equipment was negatively associated with home-based standing (Table 3, Model 3). Children spent one additional min/h standing at home for every eight musical instrument points $(p<0.01)$ and one $\mathrm{min} / \mathrm{h}$ less for every 17 media equipment points $(p<0.01)$. In the final model, a detached house (+2 $\mathrm{min}, p=0.02)$, an open plan living area $(+2 \mathrm{~min}, p=0.01)$ and musical instruments remained positively associated, while media equipment remained negatively associated with home-based standing (Table 3, Model 4). Children spent one additional min/h standing at home for every 10 musical instrument points $(p=0.01)$ and one $\mathrm{min} / \mathrm{h}$ less for every 17 media equipment points $(p<0.01)$.

\subsection{Associations between Physical Home Factors and the Number of Home-Based Sitting Breaks}

Following adjustment for all confounding factors, the number of home-based sitting breaks was negatively associated with digital TV $(-1$ transition/h, $p<0.01)$ and positively associated with objective garden size $(p<0.01)$ (Table 4, Model 3). The number of home-based sitting breaks was still negatively associated with digital TV ( -1 transition/h, $p=0.01)$ and positively associated with objective garden size $(p=0.03)$ in the final model (Table 4, Model 4).

\subsection{Associations Between Physical Home Factors and Home-Based TPA}

When controlling for all the confounding factors, home-based TPA was negatively associated with media equipment and positively associated with an open plan living area $(+1 \mathrm{~min} / \mathrm{h}, p=0.05)$ (Table 5, Model 3). Every 20 media equipment points $(p=0.01)$ was associated with one min/h less in home-based TPA. The number of floors in the house $(+1 \mathrm{~min} / \mathrm{h}, p=0.04)$ and an open plan living area $(+1 \mathrm{~min} / \mathrm{h}, p=0.04)$ were positively associated with home-based TPA in the final model (Table 5, Model 4).

\subsection{Associations Between Physical Home Factors and Home-Based MVPA}

Following controlling for all the confounding factors, home-based MVPA was negatively associated with media equipment, the number of smartphones at home and positively associated with an open plan living area (+1 min/h, $p=0.04)$ (Table 6, Model 3). Every 50 media equipment points $(p=0.03)$ and 1-2 increase in the number of smartphones at home $(p=0.01)$ were associated with one min/h less in home-based MVPA. In the final model, only the positive association between home-based MVPA and an open plan living area $(+1 \mathrm{~min} / \mathrm{h}, p=0.05)$ remained (Table 6, Model 4). 
Table 2. Associations between physical home factors and children's home-based sitting.

\begin{tabular}{|c|c|c|c|c|c|c|c|c|c|c|c|c|}
\hline \multirow{2}{*}{ Variable } & \multicolumn{3}{|c|}{ Model 1} & \multicolumn{3}{|c|}{ Model 2} & \multicolumn{3}{|c|}{ Model 3} & \multicolumn{3}{|c|}{ Model 4} \\
\hline & B (SE) & $\beta$ & $p$ & B (SE) & $\beta$ & $p$ & B (SE) & $\beta$ & $P$ & B (SE) & $\beta$ & $p$ \\
\hline Perceived house size & $-1.56(0.71)$ & -0.16 & $0.03 *$ & $-2.24(0.75)$ & -0.23 & $0.01 *$ & $-1.98(0.77)$ & -0.20 & 0.01 * & $-1.77(0.77)$ & -0.18 & $0.02 *$ \\
\hline Objective house size & $-0.01(0.01)$ & -0.05 & 0.52 & $-0.01(0.01)$ & 0.07 & 0.36 & $-0.01(0.01)$ & -0.10 & 0.24 & - & - & - \\
\hline Detached house & $-1.27(0.89)$ & -0.10 & 0.15 & $-2.31(0.92)$ & -0.19 & 0.01 & $-2.12(0.94)$ & -0.17 & $0.03 *$ & $-1.29(0.93)$ & -0.10 & 0.17 \\
\hline Number of floors & $-0.28(0.95)$ & -0.02 & 0.77 & $-0.36(0.96)$ & -0.03 & 0.71 & $-0.53(0.97)$ & -0.04 & 0.59 & - & - & - \\
\hline Open plan living area & $-2.39(0.84)$ & -0.20 & $0.01 *$ & $-2.58(0.85)$ & -0.22 & $0.01 *$ & $-2.43(0.86)$ & -0.20 & 0.01 * & $-2.62(0.81)$ & -0.22 & $<0.01$ * \\
\hline TV in child's bedroom & $1.99(0.84)$ & 0.17 & $0.02 *$ & $1.76(0.88)$ & 0.15 & 0.05 * & $1.92(0.89)$ & 0.16 & 0.03 * & $0.66(1.15)$ & 0.06 & 0.57 \\
\hline Number of living areas with TV & $0.67(0.68)$ & 0.07 & 0.32 & $0.38(0.69)$ & 0.04 & 0.59 & $0.75(0.70)$ & 0.08 & 0.29 & - & - & - \\
\hline PA equipment ${ }^{1}$ & $0.00(0.01)$ & 0.00 & 0.97 & $-0.01(0.01)$ & -0.03 & 0.66 & $-0.00(0.01)$ & -0.02 & 0.83 & - & - & - \\
\hline Seated furniture ${ }^{1}$ & $0.00(0.01)$ & 0.01 & 0.94 & $-0.01(0.02)$ & -0.03 & 0.74 & $-0.01(0.02)$ & -0.03 & 0.70 & - & - & - \\
\hline Media equipment ${ }^{1}$ & $0.08(0.02)$ & 0.26 & $<0.01 *$ & $0.08(0.02)$ & 0.24 & $<0.01 *$ & $0.08(0.02)$ & 0.25 & $<0.01 *$ & $0.08(0.03)$ & 0.23 & $<0.01$ * \\
\hline Bedroom media equipment ${ }^{1}$ & $0.18(0.07)$ & 0.19 & $0.01 *$ & $0.14(0.07)$ & 0.15 & $0.05 *$ & $0.15(0.07)$ & 0.16 & $0.03 *$ & $0.01(0.01)$ & 0.01 & 0.90 \\
\hline Musical instruments ${ }^{1}$ & $-0.11(0.06)$ & -0.15 & $0.04 *$ & $-0.14(0.06)$ & -0.18 & 0.01 * & $-0.18(0.06)$ & -0.23 & $<0.01$ * & $-0.15(0.06)$ & -0.19 & 0.01 * \\
\hline Digital TV & $0.94(1.08)$ & 0.06 & 0.39 & $0.82(1.05)$ & 0.06 & 0.44 & $1.06(1.08)$ & 0.07 & 0.33 & - & - & - \\
\hline Movie/TV streaming & $1.26(1.00)$ & 0.09 & 0.21 & $1.14(1.00)$ & 0.08 & 0.26 & $0.90(1.03)$ & 0.06 & 0.38 & - & - & - \\
\hline Number of smartphones & $0.62(0.65)$ & 0.07 & 0.34 & $0.89(0.68)$ & 0.10 & 0.19 & $1.14(0.73)$ & 0.12 & 0.12 & - & - & - \\
\hline Space to play inside & $-0.87(0.62)$ & -0.10 & 0.16 & $-0.59(0.61)$ & -0.07 & 0.33 & $-0.57(0.62)$ & -0.07 & 0.36 & - & - & - \\
\hline Perceived garden size & $-0.32(0.57)$ & -0.04 & 0.57 & $-0.17(0.56)$ & -0.02 & 0.77 & $0.07(0.57)$ & 0.01 & 0.90 & - & - & - \\
\hline Objective garden size & $-0.00(0.00)$ & -0.10 & 0.17 & $-0.01(0.00)$ & -0.14 & 0.08 & $-0.00(0.00)$ & -0.12 & 0.13 & - & - & - \\
\hline Space to play in front garden & $-0.12(0.35)$ & -0.02 & 0.74 & $-0.01(0.35)$ & -0.00 & 0.99 & $0.06(0.35)$ & 0.01 & 0.88 & - & - & - \\
\hline \multirow{2}{*}{ Space to play in back garden } & $-0.75(0.58)$ & -0.09 & 0.20 & $-0.51(0.57)$ & -0.07 & 0.38 & $-0.49(0.59)$ & -0.06 & 0.41 & - & - & - \\
\hline & & & & & & & & & & $R^{2}(a$ & $\left.R^{2}\right) 0$ & \\
\hline
\end{tabular}

* $p \leq 0.05$ in model 1, 2 and $4 ;{ }^{*} p \leq 0.10$ in model $3 .{ }^{1}$ Accessibility and availability equipment score. Model 1: Unadjusted models for each physical factor. Model 2: Model for each physical factor adjusting for child BMI, age and sex, and the number of siblings, home ownership, season, WIMD and daylength. Model 3: Model for each physical factor adjusting for child BMI, age and sex, and the number of siblings, home ownership, season, WIMD, daylength, child preferences for sedentary or PA activities, parent preferences for sedentary or PA activities, parent perception of the importance of their child engaging in active play and a maximum h/day of screen-time rule. Model 4: Final model including all significant physical factors from models 3, adjusting for child BMI, age and sex, and the number of siblings, home ownership, season, WIMD, daylength, child preferences for sedentary or PA activities, parent preferences for sedentary or PA activities, parent perception of the importance of their child engaging in active play and a maximum $\mathrm{h} /$ day of screen-time rule. 
Table 3. Associations between physical home factors and children's home-based standing.

\begin{tabular}{|c|c|c|c|c|c|c|c|c|c|c|c|c|}
\hline \multirow{2}{*}{ Variable } & \multicolumn{3}{|c|}{ Model 1} & \multicolumn{3}{|c|}{ Model 2} & \multicolumn{3}{|c|}{ Model 3} & \multicolumn{3}{|c|}{ Model 4} \\
\hline & B (SE) & $\beta$ & $p$ & B (SE) & $\beta$ & $p$ & B (SE) & $\beta$ & $p$ & B (SE) & $\beta$ & $p$ \\
\hline Perceived house Size & $1.01(0.51)$ & 0.14 & $0.05^{*}$ & $1.40(0.53)$ & 0.20 & $0.01 *$ & $1.28(0.55)$ & 0.18 & $0.02 *$ & $0.96(0.54)$ & 0.13 & 0.08 \\
\hline Objective house size & $0.00(0.01)$ & 0.03 & 0.67 & $0.00(0.01)$ & 0.04 & 0.66 & $0.00(0.01)$ & 0.05 & 0.54 & - & - & - \\
\hline Detached house & $1.36(0.62)$ & 0.16 & $0.03 *$ & $1.97(0.64)$ & 0.22 & $<0.01$ * & $2.09(0.66)$ & 0.24 & $<0.01$ * & $1.61(0.66)$ & 0.18 & $0.02 *$ \\
\hline Number of floors & $-0.40(0.67)$ & -0.04 & 0.55 & $-0.17(0.68)$ & -0.02 & 0.81 & $-0.16(0.69)$ & -0.02 & 0.82 & - & - & - \\
\hline Open plan living area & $1.37(0.60)$ & 0.16 & $0.02 *$ & $1.58(0.61)$ & 0.19 & $0.01 *$ & $1.54(0.62)$ & 0.18 & $0.01 *$ & $1.58(0.58)$ & 0.19 & 0.01 * \\
\hline TV in child's bedroom & $-1.19(0.59)$ & -0.14 & $0.05 *$ & $-1.03(0.62)$ & -0.12 & 0.10 & $-1.01(0.64)$ & -0.12 & 0.12 & - & - & - \\
\hline Number of living areas with TV & $-0.55(0.48)$ & -0.08 & 0.25 & $-0.45(0.49)$ & -0.07 & 0.36 & $-0.59(0.50)$ & -0.09 & 0.24 & - & - & - \\
\hline PA equipment ${ }^{1}$ & $-0.00(0.01)$ & -0.01 & 0.88 & $0.00(0.01)$ & 0.03 & 0.69 & $-0.00(0.01)$ & -0.03 & 0.68 & - & - & - \\
\hline Seated furniture ${ }^{1}$ & $-0.00(0.01)$ & -0.01 & 0.85 & $0.01(0.01)$ & 0.03 & 0.66 & $0.01(0.01)$ & 0.04 & 0.63 & - & - & - \\
\hline Media equipment ${ }^{1}$ & $-0.06(0.02)$ & -0.27 & $<0.01$ * & $-0.06(0.02)$ & -0.24 & $<0.01$ * & $-0.06(0.02)$ & -0.24 & $<0.01$ * & $-0.06(0.02)$ & -0.24 & $<0.01 *$ \\
\hline Bedroom media equipment ${ }^{1}$ & $-0.11(0.05)$ & -0.17 & $0.02 *$ & $-0.07(0.05)$ & -0.11 & 0.13 & $-0.07(0.05)$ & -0.11 & 0.16 & - & - & - \\
\hline Musical instruments ${ }^{1}$ & $0.09(0.04)$ & 0.17 & $0.02 *$ & $0.10(0.04)$ & 0.19 & $0.01 *$ & $0.12(0.04)$ & 0.22 & $<0.01$ * & $0.10(0.04)$ & 0.18 & 0.01 * \\
\hline Digital TV & $-0.97(0.76)$ & -0.09 & 0.20 & $-0.78(0.74)$ & -0.07 & 0.29 & $-0.88(0.77)$ & -0.08 & 0.25 & - & - & - \\
\hline Movie/TV streaming & $-1.18(0.70)$ & -0.12 & 0.10 & $-1.20(0.71)$ & -0.12 & 0.09 & $-1.04(0.73)$ & -0.10 & 0.16 & - & - & - \\
\hline Number of smartphones & $-0.64(0.46)$ & -0.10 & 0.16 & $-0.67(0.48)$ & -0.11 & 0.16 & $-0.61(0.53)$ & -0.09 & 0.25 & - & - & - \\
\hline Space to play inside & $0.37(0.45)$ & 0.06 & 0.41 & $0.07(0.43)$ & 0.01 & 0.87 & $0.08(0.44)$ & 0.01 & 0.87 & - & - & - \\
\hline Perceived garden size & $-0.21(0.40)$ & -0.04 & 0.60 & $-0.33(0.40)$ & -0.06 & 0.41 & $-0.39(0.41)$ & -0.07 & 0.34 & - & - & - \\
\hline Objective garden size & $0.00(0.00)$ & 0.05 & 0.48 & $0.00(0.00)$ & -0.06 & 0.41 & $0.00(0.00)$ & 0.07 & 0.40 & - & - & - \\
\hline Space to play in front garden & $0.09(0.25)$ & 0.02 & 0.74 & $-0.04(0.25)$ & -0.01 & 0.89 & $-0.06(0.25)$ & -0.02 & 0.83 & - & - & - \\
\hline Space to play in back garden & $0.31(0.42)$ & 0.05 & 0.46 & $0.10(0.41)$ & 0.02 & 0.80 & $0.11(0.42)$ & 0.02 & 0.80 & - & - & - \\
\hline
\end{tabular}

* $p \leq 0.05$ in model 1, 2 and $4 ;{ }^{*} p \leq 0.10$ in model $3 ;{ }^{1}$ Accessibility and availability equipment score. Model 1: Unadjusted models for each physical factor; Model 2: Model for each physical factor adjusting for child BMI, age and sex, and the number of siblings, home ownership, season, WIMD and daylength; Model 3: Model for each physical factor adjusting for child BMI, age and sex, and the number of siblings, home ownership, season, WIMD, daylength, child preferences for sedentary or PA activities, parent preferences for sedentary or PA activities, parent perception of the importance of their child engaging in active play and a maximum h/day of screen-time rule; Model 4: Final model including all significant physical factors from models 3, adjusting for child BMI, age and sex, and the number of siblings, home ownership, season, WIMD, daylength, child preferences for sedentary or PA activities, parent preferences for sedentary or PA activities, parent perception of the importance of their child engaging in active play and a maximum $\mathrm{h} /$ day of screen-time rule. 
Table 4. Associations between physical home factors and children's home-based sitting breaks.

\begin{tabular}{|c|c|c|c|c|c|c|c|c|c|c|c|c|}
\hline \multirow{2}{*}{ Variable } & \multicolumn{3}{|c|}{ Model 1} & \multicolumn{3}{|c|}{ Model 2} & \multicolumn{3}{|c|}{ Model 3} & \multicolumn{3}{|c|}{ Model 4} \\
\hline & B (SE) & $\beta$ & $p$ & B (SE) & $\beta$ & $p$ & B (SE) & $\beta$ & $p$ & B (SE) & $\beta$ & $p$ \\
\hline Perceived house Size & $0.37(0.23)$ & 0.12 & 0.10 & $0.41(0.23)$ & 0.13 & 0.08 & $0.39(0.23)$ & 0.12 & $0.10^{*}$ & $0.05(0.25)$ & 0.01 & 0.86 \\
\hline Objective house size & $0.00(0.00)$ & 0.11 & 0.13 & $0.00(0.00)$ & 0.11 & 0.15 & $0.00(0.00)$ & 0.11 & 0.15 & $-.00(0.20)$ & - & - \\
\hline Detached house & $0.13(0.28)$ & 0.03 & 0.64 & $0.11(0.28)$ & 0.03 & 0.70 & $0.11(0.29$ & 0.03 & 0.72 & - & - & - \\
\hline Number of floors & $0.21(0.30)$ & 0.05 & 0.49 & $0.34(0.29)$ & 0.08 & 0.23 & $0.36(0.29)$ & 0.09 & 0.23 & - & _- & _- \\
\hline Open plan living area & $0.08(0.27)$ & 0.20 & 0.78 & $0.03(0.26)$ & 0.01 & 0.91 & $-0.10(0.27)$ & -0.03 & 0.71 & _- & _- & - \\
\hline TV in child's bedroom & $-0.73(0.27)$ & -0.20 & $0.01 *$ & $-0.43(0.26)$ & -0.12 & 0.11 & $-0.37(0.27)$ & -0.10 & 0.18 & _- & _- & _- \\
\hline Number of living areas with TV & $-0.25(0.22)$ & -0.09 & 0.24 & $-0.20(0.21)$ & -0.07 & 0.35 & $-0.20(0.21)$ & -0.07 & 0.36 & - & - & - \\
\hline PA equipment ${ }^{1}$ & $0.00(0.00)$ & -0.01 & 0.86 & $0.00(0.00)$ & 0.00 & 1.0 & $-0.01(0.00)$ & -0.02 & 0.81 & _- & _- & _- \\
\hline Seated furniture ${ }^{1}$ & $0.00(0.01)$ & 0.05 & 0.46 & $0.01(0.01)$ & 0.13 & 0.07 & $0.01(0.00)$ & 0.14 & $0.06^{*}$ & $0.00(0.01)$ & 0.05 & 0.49 \\
\hline Media equipment ${ }^{1}$ & $-0.02(0.01)$ & -0.20 & $0.04 *$ & $-0.01(0.01)$ & -0.08 & 0.25 & $-0.01(0.01)$ & -0.05 & 0.46 & - & - & - \\
\hline Bedroom media equipment ${ }^{1}$ & $-0.04(0.02)$ & -0.15 & $0.04 *$ & $-0.02(0.02)$ & -0.06 & 0.39 & $-0.01(0.02)$ & -0.05 & 0.51 & - & - & - \\
\hline Musical instruments 1 & $0.02(0.02)$ & 0.09 & 0.22 & $0.02(0.02)$ & 0.07 & 0.33 & $0.01(0.02)$ & 0.05 & 0.49 & - & - & - \\
\hline Digital TV & $-1.08(0.33)$ & -0.23 & $<0.01$ * & $-1.11(0.31)$ & -0.24 & $<0.01 *$ & $-0.99(0.32)$ & -0.21 & $<0.01 *$ & $-0.86(0.32)$ & -0.18 & 0.01 * \\
\hline Movie/TV streaming & $-0.33(0.32)$ & -0.08 & 0.30 & $-0.10(0.30)$ & -0.02 & 0.75 & $0.02(0.31)$ & 0.00 & 0.96 & $-0.00(0.01$ & -10 & - \\
\hline Number of smartphones & $-0.33(0.21)$ & -0.12 & 0.11 & $-0.29(0.21)$ & -0.10 & 0.15 & $-0.24(0.22)$ & -0.08 & 0.29 & - & - & - \\
\hline Space to play inside & $0.49(0.19)$ & 0.18 & $0.01 *$ & $0.36(0.18)$ & 0.14 & $0.05 *$ & $0.35(0.19)$ & 0.13 & $0.06^{*}$ & $0.35(0.20)$ & 0.13 & 0.08 \\
\hline Perceived garden size & $0.16(0.18)$ & 0.06 & 0.39 & $0.19(0.17)$ & 0.08 & 0.26 & $0.16(0.17)$ & 0.07 & 0.35 & -.201 & - & - \\
\hline Objective garden size & $0.00(0.00)$ & 0.22 & $<0.01 *$ & $0.00(0.00)$ & 0.23 & $<0.01$ * & $0.00(0.00)$ & 0.22 & $<0.01 *$ & $0.00(0.00)$ & 0.16 & $0.03 *$ \\
\hline Space to play in front garden & $0.12(0.11)$ & 0.08 & 0.29 & $0.06(0.11)$ & 0.04 & 0.56 & $0.03(0.11)$ & 0.02 & 0.77 & $0.00(0.00)$ & 0.10 & - \\
\hline Space to play in back garden & $0.30(0.18)$ & 0.12 & 0.10 & $0.29(0.17)$ & 0.12 & 0.09 & $0.26(0.18)$ & 0.11 & 0.14 & - & - & - \\
\hline
\end{tabular}

* $p \leq 0.05$ in model 1, 2 and $4 ;{ }^{*} p \leq 0.10$ in model $3 ;{ }^{1}$ Accessibility and availability equipment score; Model 1: Unadjusted models for each physical factor; Model 2: Model for each physical factor adjusting for child BMI, age and sex, and the number of siblings, home ownership, season, WIMD and daylength; Model 3: Model for each physical factor adjusting for child BMI, age and sex, and the number of siblings, home ownership, season, WIMD, daylength, child preferences for sedentary or PA activities, parent preferences for sedentary or PA activities, parent perception of the importance of their child engaging in active play and a maximum h/day of screen-time rule; Model 4: Final model including all significant physical factors from models 3, adjusting for child BMI, age and sex, and the number of siblings, home ownership, season, WIMD, daylength, child preferences for sedentary or PA activities, parent preferences for sedentary or PA activities, parent perception of the importance of their child engaging in active play and a maximum $\mathrm{h} /$ day of screen-time rule. 
Table 5. Associations between physical home factors and children's home-based TPA.

\begin{tabular}{|c|c|c|c|c|c|c|c|c|c|c|c|c|}
\hline \multirow{2}{*}{ Variable } & \multicolumn{3}{|c|}{ Model 1} & \multicolumn{3}{|c|}{ Model 2} & \multicolumn{3}{|c|}{ Model 3} & \multicolumn{3}{|c|}{ Model 4} \\
\hline & B (SE) & $\beta$ & $P$ & B (SE) & $\beta$ & $P$ & B (SE) & $\beta$ & $P$ & B (SE) & $\beta$ & $P$ \\
\hline Perceived house size & $0.33(0.57)$ & 0.04 & 0.56 & $0.48(0.58)$ & 0.06 & 0.41 & $0.30(0.59)$ & 0.04 & 0.62 & - & - & - \\
\hline Objective house size & $0.00(0.01)$ & 0.01 & 0.90 & $0.00(0.01)$ & 0.03 & 0.68 & $0.00(0.01)$ & 0.04 & 0.58 & - & - & - \\
\hline Detached house & $-0.91(0.70)$ & -0.09 & 0.20 & $-0.82(0.70)$ & -0.08 & 0.24 & $-0.91(0.71)$ & -0.09 & 0.21 & - & _- & _- \\
\hline Number of floors & $1.04(0.76)$ & 0.10 & 0.17 & $1.20(0.73)$ & 0.11 & 0.10 & $1.28(0.74)$ & 0.12 & $0.09 *$ & $1.48(0.73)$ & 0.14 & 0.04 * \\
\hline Open plan living area & $1.63(0.67)$ & 0.17 & $0.02 *$ & $1.57(0.65)$ & 0.16 & $0.02 *$ & $1.34(0.67)$ & 0.14 & $0.05 *$ & $1.34(0.66)$ & 0.14 & 0.04 * \\
\hline TV in child's bedroom & $-1.99(0.66)$ & -0.22 & $<0.01 *$ & $-1.10(0.67)$ & -0.12 & 0.10 & $-1.04(0.68)$ & -0.11 & 0.13 & - & - & - \\
\hline Number of living areas with TV & $-0.83(0.53)$ & -0.11 & 0.12 & $-0.80(0.51)$ & -0.11 & 0.11 & $-0.93(0.52)$ & -0.13 & $0.08^{*}$ & $-0.79(0.55)$ & -0.11 & 0.15 \\
\hline PA equipment ${ }^{1}$ & $-0.01(0.01)$ & -0.07 & 0.36 & $0.00(0.01)$ & -0.00 & 0.97 & $-0.00(0.01)$ & -0.02 & 0.78 & - & - & - \\
\hline Seated furniture ${ }^{1}$ & $-0.01(0.01)$ & 0.03 & 0.63 & $-0.01(0.01)$ & -0.03 & 0.64 & $-0.01(0.01)$ & 0.04 & 0.61 & - & - & - \\
\hline Media equipment ${ }^{1}$ & $-0.07(0.02)$ & -0.26 & $<0.01$ * & $-0.05(0.02)$ & -0.19 & $0.01 *$ & $-0.05(0.02)$ & -0.18 & $0.01 *$ & $-0.04(0.02)$ & -0.13 & 0.10 \\
\hline Bedroom media equipment ${ }^{1}$ & $-0.11(0.05)$ & -0.14 & $0.05^{*}$ & $-0.03(0.05)$ & -0.05 & 0.53 & $-0.03(0.05)$ & -0.04 & 0.56 & - & - & - \\
\hline Musical instruments 1 & $0.05(0.05)$ & 0.08 & 0.25 & $0.04(0.04)$ & 0.07 & 0.34 & $0.05(0.05)$ & 0.07 & 0.31 & _- & _- & - \\
\hline Digital TV & $-1.06(0.85)$ & -0.09 & 0.22 & $-1.06(0.80)$ & -0.09 & 0.19 & $-0.93(0.83)$ & -0.08 & 0.27 & - & - & - \\
\hline Movie/TV streaming & $-1.35(0.80)$ & -0.12 & 0.09 & $-0.78(0.77)$ & -0.07 & 0.31 & $-0.53(0.79)$ & -0.05 & 0.50 & - & - & - \\
\hline Number of smartphones & $-1.21(0.51)$ & -0.17 & $0.02 *$ & $-1.04(0.52)$ & -0.14 & 0.05 & $-0.96(0.57)$ & -0.12 & 0.09 & $-0.45(0.61)$ & -0.06 & 0.46 \\
\hline Space to play inside & $0.59(0.49)$ & 0.09 & 0.23 & $0.25(0.47)$ & 0.04 & 0.59 & $0.13(0.48)$ & 0.02 & 0.79 & - & - & - \\
\hline Perceived garden size & $-0.09(0.45)$ & -0.02 & 0.84 & $-0.04(0.43)$ & -0.01 & 0.93 & $-0.18(0.44)$ & -0.03 & 0.69 & - & - & - \\
\hline Objective garden size & $0.00(0.00)$ & 0.09 & 0.19 & $0.00(0.00)$ & 0.14 & 0.06 & $0.00(0.00)$ & 0.12 & 0.12 & - & - & - \\
\hline & $0.00(0.28)$ & 0.00 & 1.00 & $-0.06(0.27)$ & -0.02 & 0.82 & $-0.13(0.27)$ & -0.03 & 0.63 & - & - & - \\
\hline \multirow{2}{*}{ Space to play in back garden } & $0.55(0.46)$ & 0.09 & 0.24 & $0.44(0.44)$ & 0.07 & 0.31 & $0.31(0.45)$ & 0.05 & 0.49 & - & - & - \\
\hline & & & & & & & & & & \multicolumn{3}{|c|}{$\mathrm{R}^{2}\left(\right.$ adjusted $\left.\mathrm{R}^{2}\right) 0.28(0.21)$} \\
\hline
\end{tabular}

* $p \leq 0.05$ in model 1, 2 and $4 ;{ }^{*} p \leq 0.10$ in model $3 ;{ }^{1}$ Accessibility and availability equipment score. Model 1: Unadjusted models for each physical factor. Model 2: Model for each physical factor adjusting for child BMI, age and sex, and the number of siblings, home ownership, season, WIMD and daylength. Model 3: Model for each physical factor adjusting for child BMI, age and sex, and the number of siblings, home ownership, season, WIMD, daylength, child preferences for sedentary or PA activities, parent preferences for sedentary or PA activities, parent perception of the importance of their child engaging in active play and a maximum h/day of screen-time rule; Model 4: Final model including all significant physical factors from models 3, adjusting for child BMI, age and sex, and the number of siblings, home ownership, season, WIMD, daylength, child preferences for sedentary or PA activities, parent preferences for sedentary or PA activities, parent perception of the importance of their child engaging in active play and a maximum $\mathrm{h} / \mathrm{days}$ of screen-time rule. 
Table 6. Associations between physical home factors and children's home-based MVPA.

\begin{tabular}{|c|c|c|c|c|c|c|c|c|c|c|c|c|}
\hline \multirow{2}{*}{ Variable } & \multicolumn{3}{|c|}{ Model 1} & \multicolumn{3}{|c|}{ Model 2} & \multicolumn{3}{|c|}{ Model 3} & \multicolumn{3}{|c|}{ Model 4} \\
\hline & B (SE) & $\beta$ & $p$ & B (SE) & $\beta$ & $p$ & B (SE) & $\beta$ & $p$ & B (SE) & $\beta$ & $p$ \\
\hline Perceived house size & $0.24(0.28)$ & 0.06 & 0.39 & $0.31(0.28)$ & 0.08 & 0.26 & $0.18(0.28)$ & 0.05 & 0.53 & - & - & - \\
\hline Objective house size & $0.00(0.00)$ & 0.02 & 0.76 & $0.00(0.00)$ & 0.05 & 0.51 & $0.00(0.00)$ & 0.06 & 0.44 & - & - & - \\
\hline Detached house & $-0.56(0.34)$ & -0.12 & 0.10 & $-0.42(0.33)$ & -0.09 & 0.21 & $-0.54(0.34)$ & -0.11 & 0.11 & - & - & - \\
\hline Number of floors & $0.52(0.36)$ & 0.10 & 0.15 & $0.50(0.35)$ & 0.10 & 0.15 & $0.57(0.35)$ & 0.11 & 0.11 & - & - & - \\
\hline Open plan living area & $0.88(0.32)$ & 0.19 & $0.01 *$ & $0.73(0.31)$ & 0.16 & $0.02 *$ & $0.66(0.32)$ & 0.14 & $0.04 *$ & $0.63(0.32)$ & 0.14 & $0.05 *$ \\
\hline TV in child's bedroom & $-0.85(0.32)$ & -0.19 & $0.01 *$ & $-0.48(0.32)$ & -0.11 & 0.13 & $-0.49(0.32)$ & -0.11 & 0.13 & - & - & - \\
\hline Number of living areas with TV & $-0.28(0.25)$ & -0.08 & 0.27 & $-0.23(0.24)$ & -0.06 & 0.36 & $-0.37(0.25)$ & -0.11 & 0.13 & - & - & - \\
\hline PA equipment ${ }^{1}$ & $-0.00(0.00)$ & -0.03 & 0.67 & $0.00(0.00)$ & 0.03 & 0.66 & $0.00(0.00)$ & 0.01 & 0.91 & - & - & - \\
\hline Seated furniture ${ }^{1}$ & $0.00(0.01)$ & 0.00 & 0.95 & $-0.00(0.01)$ & -0.02 & 0.81 & $-0.00(0.01)$ & -0.03 & 0.73 & - & - & - \\
\hline Media equipment ${ }^{1}$ & $-0.03(0.01)$ & -0.21 & $<0.01$ * & $-0.02(0.01)$ & -0.15 & $0.03 *$ & $-0.02(0.01)$ & -0.15 & 0.03 * & $-0.01(0.01)$ & -0.08 & 0.28 \\
\hline Bedroom media equipment ${ }^{1}$ & $-0.05(0.03)$ & -0.14 & $0.06^{*}$ & $-0.02(0.03)$ & -0.06 & 0.36 & $-0.03(0.03)$ & -0.07 & 0.31 & - & - & - \\
\hline Musical instruments ${ }^{1}$ & $0.02(0.02)$ & 0.08 & 0.29 & $0.02(0.02)$ & 0.06 & 0.39 & $0.03(0.02)$ & 0.09 & 0.23 & - & - & - \\
\hline Digital TV & $-0.43(0.41)$ & -0.08 & 0.29 & $-0.37(0.39)$ & -0.06 & 0.34 & $-0.40(0.40)$ & -0.07 & 0.31 & - & - & - \\
\hline Movie/TV streaming & $-0.48(0.39)$ & -0.09 & 0.21 & $-0.36(0.37)$ & -0.07 & 0.32 & $-0.27(0.38)$ & -0.05 & 0.47 & - & - & - \\
\hline Number of smartphones & $-0.63(0.25)$ & -0.18 & 0.01 * & $-0.60(0.25)$ & -0.17 & $0.02 *$ & $-0.69(0.27)$ & -0.18 & 0.01 * & $-0.49(0.30)$ & -0.13 & 0.11 \\
\hline Perceived garden size & $0.25(0.22)$ & 0.08 & 0.25 & $0.26(0.21)$ & 0.09 & 0.20 & $0.17(0.21)$ & 0.06 & 0.42 & - & - & - \\
\hline Objective garden size & $0.00(0.00)$ & 0.10 & 0.16 & $0.00(0.00)$ & 0.16 & $0.03 *$ & $0.00(0.00)$ & 0.13 & $0.07^{*}$ & $0.00(0.00)$ & 0.09 & 0.20 \\
\hline Space to play in front garden & $-0.12(0.13)$ & -0.06 & 0.38 & $-0.14(0.13)$ & -0.08 & 0.27 & $-0.17(0.13)$ & -0.09 & 0.18 & - & - & - \\
\hline Space to play in back garden & $0.25(0.22)$ & 0.08 & 0.26 & $0.21(0.21)$ & 0.07 & 0.33 & $0.15(0.22)$ & 0.05 & 0.47 & - & - & - \\
\hline
\end{tabular}

${ }^{*} p \leq 0.05$ in model 1, 2 and $4 ;{ }^{*} p \leq 0.10$ in model $3 ;{ }^{1}$ Accessibility and availability equipment score. Model 1: Unadjusted models for each physical factor. Model 2: Model for each physical factor adjusting for child BMI, age and sex, and the number of siblings, home ownership, season, WIMD and daylength. Model 3: Model for each physical factor adjusting for child BMI, age and sex, and the number of siblings, home ownership, season, WIMD, daylength, child preferences for sedentary or PA activities, parent preferences for sedentary or PA activities, parent perception of the importance of their child engaging in active play and a maximum h/day of screen-time rule. Model 4: Final model including all significant physical factors from models 3, adjusting for child BMI, age and sex, and the number of siblings, home ownership, season, WIMD, daylength, child preferences for sedentary or PA activities, parent preferences for sedentary or PA activities, parent perception of the importance of their child engaging in active play and a maximum h/day of screen-time rule. 


\section{Discussion}

This study identified several previously unexplored physical factors within the home as correlates of children's sitting, standing and PA at home. An open plan living area, the number of floors, musical instrument accessibility and availability as well as objective garden size were significantly influential, although, given these relationships have not been investigated before, it is difficult to make comparisons with past work. This is one of the first in the field to use a posture monitor and to examine home-based PA and sedentary time and found that children spent $46 \%$ of their time at home, which reinforces the importance of investigating the correlates of PA and sedentary time in this environment.

The layout of the family home as open plan living, compared with a more segmented living space was shown in this study to be independently associated with less sitting, more standing, more TPA and more MVPA irrespective of demographic factors, the social environment and other significant home factors. According to qualitative research [23,57], the lack of dividing walls in open plan living areas enable parents to better monitor electronic media usage and enforce rules. Indeed, electronic media rules have been shown to be associated with lower screen-time in children $[17,58]$. Furthermore, open-plan design may also provide more space to accommodate alternatives to screen-based pursuits [57].

This study is the first to include a measure of the number of floors in houses, observing a significant positive association with TPA. Additional floors in houses may result in higher TPA via increased stair usage. Indeed, the energy cost of stair climbing in children is between 5.3 and 8.8 METs [26], which is considered moderate-to-vigorous intensity. However, the relationship did not reach significance until the final model, implying the relationship is mediated by other physical environmental factors associated with TPA. This would suggest that the number of floors in houses is not uniquely associated with TPA.

Our findings showed that increased perceived, but not objective, house size, was associated with less sitting. This may suggest that perceived and objective house size have differential effects on sitting, yet it may also be because of the way objective house size was measured. It is possible that the objective house size measure may not be a true measure of size, as it was not the exact house size, but instead the median size of houses in the same postcode unit. One previous study [59], reported no association between self-reported house size and sedentary time among Spanish children aged 9-18 years. This discrepancy may be due to the present study measuring home-based sedentary time, and not sedentary time across the entire day. Indeed, it might be that only home-based, not overall, sedentary time is influenced by house size. A study that examined the influence of spatial organisation in homes on activity found adults in houses with higher integration between rooms (greater interconnectedness) spent more time sedentary, particularly watching TV [60]. The mechanism proposed for this was that a greater interconnectedness between rooms encourages social interaction, which in turn can lead to increased time spent in sedentary activities that are susceptible to social life in homes such as TV viewing. Larger houses may have less interconnectedness overall, as they have more rooms, and the average connectivity between rooms does not increase in larger houses [60]. Although speculative, a higher interconnectedness amongst rooms in smaller houses may increase sitting time by prompting participation in social sedentary activities such as TV viewing.

Increased accessibility and availability of musical instruments was associated with less sitting and more standing at home, which is interesting as many musical instruments can be played sitting or standing [26]. Playing musical instruments may displace sitting activities, such as screen-time, studying, socialising, and increase standing periods. Future research should seek to investigate this relationship further, particularly given the cognitive benefits of playing a musical instrument [61].

There was a strong association between greater accessibility and availability of media equipment and reduced standing and increased sitting at home, which was robust to adjustment for social and demographic factors. In one of the few other studies to have a combined measure of the accessibility and availability of media equipment, a positive relationship was found with screen-time in girls, but not with overall sedentary time in either sex [19]. Most studies [19,62], but not all [59], have shown no association between household media equipment and overall sedentary time. Moreover, 
bedroom media equipment was positively associated with sitting, but not after adjusting for the other significant factors, in contrast to previous studies that have predominantly shown no association [63-65]. The present study used a posture monitor, whereas others have used accelerometery $[16,64]$, which is considered a less accurate measure of sitting [66]. Whilst the lack of a relationship between bedroom media equipment and MVPA is congruent with previous research [63,64], some studies found contradictory results $[67,68]$. Such contradictory findings may be attributable to, at least in part, methodological differences and large inter-individual variation. Nonetheless, our findings highlight the important role the home media equipment environment may have by encouraging sitting and consequently reducing standing through acting as a prompt to engage in screen-time.

Despite the plethora of studies investigating the influence of media equipment, it is worth noting that, to our knowledge, only one previous study has measured home-based behaviour, whereby no relationship was found with bedroom media equipment and either sedentary time or PA in primary school aged children [16]. As behaviours are likely shaped by characteristics of the setting in which they occur, it is important to measure sedentary time and PA at home, to improve the understanding of the factors that influence these behaviours in this environment. Supporting this approach, screen-based behaviours, that most often occur at home [14], have been consistently positively associated with media equipment in the home $[59,62]$ and in the bedroom $[64,65]$. Therefore, further research measuring home-based sitting and PA objectively may provide some clarity on the role of media equipment in influencing children's PA and sitting.

Children with digital TV at home had fewer sitting breaks. Pay TV/digital TV has been associated with increased TV viewing in adolescents [69], and screen-time in pre-school children [70]. Therefore, a greater choice of TV channels may be compelling to children, keeping them entertained for longer periods, resulting in less frequent sitting breaks. In addition, objectively measured garden size was positively associated with sitting breaks. This would suggest that children with larger gardens have more opportunities for breaking up screen-based sedentary activities. Fittingly, objectively measured garden size was also positively associated with MVPA. However, the association was attenuated with the addition of the social factors to the model. This indicates that factors such as the importance parents place on their children engaging in active types of play and parental restrictions on screen-time explain why some children do more MVPA and have larger gardens.

Despite the inconsistencies in the literature, our findings demonstrate the potential efficacy of removing electronic media from bedrooms and limiting the electronic media presence in homes to reduce children's sitting time. Given the association between greater accessibility and availability of musical instruments and reduced sitting and increased standing, encouraging children to learn a musical instrument requires exploration as a strategy for reducing children's sitting. Considering the potential utility of an open plan living area in allowing parents to better monitor electronic media usage and accommodating alternatives to sedentary activities, moving electronic media to an area that permits parental supervision and reconfiguring furniture to create space hold promise as strategies for reducing children's sitting time and increasing their PA. Our findings also suggest that larger gardens may be important for PA, and particularly for increasing sitting breaks. This is important, given there is emerging evidence that more frequent sitting breaks are beneficially associated with metabolic indicators in children [71], particularly when interrupted with moderate walking [72]. Therefore, strategies which break up prolonged sitting such as encouraging children to take 5-min walking breaks during adverts when watching TV or after completing a level while playing video games should be incorporated into an intervention. The provision of standing or PA breaks is a strategy that has been incorporated into school-based interventions, which successfully increased PA and decreased sitting [73].

More insight into the behavioural type and broader contextual information may lead to a better understanding of the determinants of PA and sedentary time at home. Automated wearable cameras when used alongside accelerometery and inclinometers could provide important information on where the behaviour occurs, as well as the type of behaviour being performed [74]. However, given 
participants may be wearing the device in situations unsuitable for photography, research involving this technology remains problematic [75]. Radiofrequency identification and open beacon proximity tags hold potential to assess the location of behaviours at home (e.g., bedroom, lounge or kitchen); however, such technology is currently expensive and difficult to implement in homes due to their weak Wi-Fi coverage [76], compared with environments where it has been trialled previously, such as offices [77] and cares homes [78]. Technologies that provide objective contextual information for sedentary time and PA at home will mostly likely be available for use in the imminent future.

This study has numerous strengths, such as the use of the comprehensive audit to measure the physical environment, the assessment of sitting and standing using a posture sensor, the home-based measures of behaviours and the exploration of several previously unstudied physical variables. Furthermore, a wide range of important mediating factors were controlled for and the high response rate increased the representativeness of the findings. We also included both perceived and objective measures of the environment, based on recommendations of several reviews [79], as they are related to behaviours differently [80]. Nonetheless, it is important to acknowledge the limitations. Some degree of misclassification of when the children were at home is likely, as we relied on self-reporting to determine this. However, there are currently no feasible objective alternatives for measuring children's location-specific behaviours. Whilst the sample size was relatively small, it was large enough to provide reasonable statistical power [29]. Although this is one of the first studies to measure house and garden size objectively and investigate how they relate to children's PA and sitting, since full home addresses were not available, we could only obtain measures for each postcode, and not for the specific homes. Thus, the measures may not reflect the true environments, as not all homes with the same postcode are identical. Additionally, total garden and house size may not correspond to usable space where children can be active and play. Whilst we tried to account for this by measuring actual space to play inside and outside via self-reporting, space syntax software could be used in combination with floor plans to measure indoor space [81] and also the degree of integration amongst rooms [60]. Furthermore, although beyond the scope of the current study, future work should also seek to explore these relationships during the school holidays, when children are less active and more sedentary [82]. Due to the cross-sectional nature of the study, causal relationships could not be inferred. Relationships may be complex, and it is likely that social factors work in combination with the physical environment to influence behaviours. Nonetheless, these findings are novel and add valuable knowledge to the evidence base.

\section{Conclusions}

In conclusion, the results suggest that some aspects of physical home environment may have an important influence on children's sitting, standing and PA at home, even after adjusting for socio demographic and social environmental factors. Therefore, it is imperative that future interventions target this environment, especially given children in this study spent a large proportion of their time at home sitting $(67 \%)$ and the lack of previous home-based interventions [17]. Based on the results, strategies such as reconfiguring furniture to increase space, introducing electronic media breaks, promoting time spent in the garden, and housing electronic media in areas which allow parental supervision could be effective. Given the known influence of the social environment [23], and the impact of the physical environment on sitting and PA, interventions that consider both factors hold most promise. Lastly, although several physical factors are not easily modified, the findings could help impact future home and planning design to reduce sitting and increase PA and to help promote healthy active living in families.

Author Contributions: M.P.S. collected the data, assembled the input data, analysed the data and wrote the manuscript. C.M. and M.R. created the original physical and social home environment measures, contributed to the theoretical rationale of the manuscript and provided comments to drafts. G.S. and K.A.M. supervised the analyses and edited the manuscript. L.J.G. assisted with statistical analysis and edited the manuscript. R.F. obtained the objective measures of house and garden size. 
Funding: Michael P. Sheldrick is supported by a Zienkiewicz scholarship awarded by Swansea University.

Acknowledgments: The authors wish to thank the schools, the children and their parents for their participation in the HomeSPACE study. The authors would also like to acknowledge everyone who helped with data collection.

Conflicts of Interest: The authors declare no conflict of interest.

\section{References}

1. Poitras, V.J.; Gray, C.E.; Borghese, M.M.; Carson, V.; Chaput, J.-P.; Janssen, I.; Katzmarzyk, P.T.; Pate, R.R.; Connor Gorber, S.; Kho, M.E.; et al. Systematic review of the relationships between objectively measured physical activity and health indicators in school-aged children and youth. Appl. Physiol. Nutr. Metab. 2016, 41, S197-S239. [CrossRef] [PubMed]

2. Department of Health, Physical Activity, Health Improvement and Protection. Start Active, Stay Active: A Report on Physical Activity from the Four Home Countries' Chief Medical Officers. Available online: https://www.gov.uk/government/publications/start-active-stay-active-a-report-on-physical-activityfrom-the-four-home-countries-chief-medical-officers (accessed on 29 October 2019).

3. Craig, R.; Mindell, J.; Hirani, V. Health Survey for England 2008 Volume 1: Physical Activity and Fitness. Available online: https:/digital.nhs.uk/data-and-information/publications/statistical/health-survey-forengland/health-survey-for-england-2008-physical-activity-and-fitness (accessed on 29 October 2019).

4. Tremblay, M.S.; Aubert, S.; Barnes, J.D.; Saunders, T.J.; Carson, V.; Latimer-Cheung, A.E.; Chastin, S.F.M.; Altenburg, T.M.; Chinapaw, M.J.M. Sedentary Behavior Research Network (SBRN)-Terminology Consensus Project process and outcome. Int. J. Behav. Nutr. Phys. Act. 2017, 14, 75. [CrossRef] [PubMed]

5. Carson, V.; Hunter, S.; Kuzik, N.; Gray, C.E.; Poitras, V.J.; Chaput, J.-P.; Saunders, T.J.; Katzmarzyk, P.T.; Okely, A.D.; Connor Gorber, S.; et al. Systematic review of sedentary behaviour and health indicators in school-aged children and youth: An update 1. Appl. Physiol. Nutr. Metab 2016, 41, 240-265. [CrossRef] [PubMed]

6. Ku, P.-W.; Steptoe, A.; Liao, Y.; Hsueh, M.-C.; Chen, L.-J. A cut-off of daily sedentary time and all-cause mortality in adults: A meta-regression analysis involving more than 1 million participants. BMC Med. 2018, 16, 74. [CrossRef] [PubMed]

7. Chastin, S.F.M.; Egerton, T.; Leask, C.; Stamatakis, E. Meta-analysis of the relationship between breaks in sedentary behavior and cardiometabolic health. Obesity 2015, 23, 1800-1810. [CrossRef]

8. Biddle, S.J.H.; Pearson, N.; Ross, G.M.; Braithwaite, R. Tracking of sedentary behaviours of young people: A systematic review. Prev. Med. 2010, 51, 345-351. [CrossRef] [PubMed]

9. Sallis, J.F.; Owen, N.; Fotheringham, M.J. Behavioral epidemiology: A systematic framework to classify phases of research on health promotion and disease prevention. Ann. Behav. Med. 2000, 22, $294-298$. [CrossRef] [PubMed]

10. Sallis, J.F.; Cervero, R.B.; Ascher, W.; Henderson, K.A.; Kraft, M.K.; Kerr, J. an Ecological Approach To Creating Active Living Communities. Annu. Rev. Public Health 2006, 27, 297-322. [CrossRef]

11. Bronfenbrenner, U. Toward an Experimental Ecology of Human Development. Am. Psychol. 1977, 32, 513-531. [CrossRef]

12. Briggs, D.; Denman, A.; Gulliver, J.; Marley, R.; Kennedy, C.; Philips, P.; Field, K.; Crockett, R. Time activity modelling of domestic exposures to radon. J. Environ. Manag. 2003, 67, 107-120. [CrossRef]

13. Khajehzadeh, I.; Vale, B. How New Zealanders distribute their daily time between home indoors, home outdoors and out of home. Kōtuitui New Zeal. J. Soc. Sci. Online 2017, 12, 17-31. [CrossRef]

14. Liao, Y.; Intille, S.; Wolch, J.; Pentz, M.A.; Dunton, G.F. Understanding the Physical and Social Contexts of Children's Nonschool Sedentary Behavior: An Ecological Momentary Assessment Study. J. Phys. Act. Heal. 2014, 11, 588-595. [CrossRef] [PubMed]

15. Dunton, G.F.; Kawabata, K.; Intille, S.; Wolch, J.; Pentz, M.A. Assessing the Social and Physical Contexts of Children's Leisure-Time Physical Activity: An Ecological Momentary Assessment Study. Am. J. Heal. Promot. 2012, 26, 135-142. [CrossRef] [PubMed]

16. Tandon, P.; Grow, H.M.; Couch, S.; Glanz, K.; Sallis, J.F.; Frank, L.D.; Saelens, B.E. Physical and social home environment in relation to children' s overall and home-based physical activity and sedentary time. Prev. Med. 2014, 66, 39-44. [CrossRef] 
17. Maitland, C.; Stratton, G.; Foster, S.; Braham, R.; Rosenberg, M. A place for play? The influence of the home physical environment on children's physical activity and sedentary behaviour. Int. J. Behav. Nutr. Phys. Act. 2013, 10, 1. [CrossRef]

18. Arundell, L.; Fletcher, E.; Salmon, J.; Veitch, J.; Hinkley, T. The correlates of after-school sedentary behavior among children aged 5-18 years: A systematic review. BMC Public Health 2015, 16, 58. [CrossRef]

19. Sirard, J.R.; Laska, M.N.; Patnode, C.D.; Farbakhsh, K.; Lytle, L.A. Adolescent physical activity and screen time: Associations with the physical home environment. Int. J. Behav. Nutr. Phys. Act. 2010, 7, 82. [CrossRef]

20. Biddle, S.J.H.; Marshall, S.J.; Gorely, T.; Cameron, N. Temporal and Environmental Patterns of Sedentary and Active Behaviors during Adolescents' Leisure Time. Int. J. Behav. Med. 2009, 16, 278-286. [CrossRef]

21. Page, A.S.; Cooper, A.R.; Griew, P.; Jago, R. Independent mobility, perceptions of the built environment and children's participation in play, active travel and structured exercise and sport: The PEACH Project. Int. J. Behav. Nutr. Phys. Act. 2010, 7, 17. [CrossRef]

22. Trang, N.; Hong, T.; Dibley, M.; Sibbritt, D. Factors Associated with Physical Inactivity in Adolescents in Ho Chi Minh City, Vietnam. Med Sci Sport. Exerc 2009, 41, 1374-1383. [CrossRef]

23. Maitland, C.; Stratton, G.; Foster, S.; Braham, R.; Rosenberg, M. The Dynamic Family Home: A qualitative exploration of physical environmental influences on children's sedentary behaviour and physical activity within the home space. Int. J. Behav. Nutr. Phys. Act. 2014, 11, 157. [CrossRef] [PubMed]

24. The Communications Market Report Ofcom 2015. Available online: https://www.ofcom.org.uk/researchand-data/multi-sector-research/cmr/cmr15 (accessed on 29 October 2019).

25. Granich, J.; Rosenberg, M.; Knuiman, M.; Timperio, A. Understanding children's sedentary behaviour: A qualitative study of the family home environment. Health Educ. Res. 2010, 25, 199-210. [CrossRef] [PubMed]

26. Butte, N.F.; Watson, K.B.; Ridley, K.; Zakeri, I.F.; McMurray, R.G.; Pfeiffer, K.A.; Crouter, S.E.; Herrmann, S.D.; Bassett, D.R.; Long, A.; et al. A Youth Compendium of Physical Activities: Activity Codes and Metabolic Intensities. Med. Sci. Sports Exerc. 2018, 50, 246-256. [CrossRef] [PubMed]

27. Bassett, D.R.; Vachon, J.A.; Kirkland, A.O.; Howley, E.T.; Duncan, G.E.; Johnson, K.R. Energy cost of stair climbing and descending on the college alumnus questionnaire. Med. Sci. Sports Exerc. 1997, 29, 1250-1254. [CrossRef]

28. Teh, K.C.; Aziz, A.R. Heart rate, oxygen uptake, and energy cost of ascending and descending the stairs. Med. Sci. Sports Exerc. 2002, 34, 695-699.

29. Cohen, J.; Cohen, P.; West, S.G.; Aiken, L.S. Applied Multiple Regression/Correlation Analysis for the Behavioral Sciences, 3rd ed.; Lawrence Erlbaum Associates: Mahwah, NJ, USA, 2003.

30. Maitland, C.; Foster, S.; Stratton, G.; Braham, R.; Rosenberg, M. Capturing the geography of children's active and sedentary behaviours at home: The HomeSPACE measurement tool. Child. Geogr. 2018, 3285, 1-18. [CrossRef]

31. Sirard, J.R.; Nelson, M.C.; Pereira, M.A.; Lytle, L.A. Validity and reliability of a home environment inventory for physical activity and media equipment. Int. J. Behav. Nutr. Phys. Act. 2008, 5, 24. [CrossRef]

32. Aminian, S.; Hinckson, E.A. Examining the validity of the ActivPAL monitor in measuring posture and ambulatory movement in children. Int. J. Behav. Nutr. Phys. Act. 2012, 9, 119. [CrossRef]

33. Winkler, E.A.H.; Bodicoat, D.H.; Healy, G.N.; Bakrania, K.; Yates, T.; Owen, N.; Dunstan, D.W.; Edwardson, C.L. Identifying adults' valid waking wear time by automated estimation in activPAL data collected with a $24 \mathrm{~h}$ wear protocol. Physiol. Meas. 2016, 37, 1653-1668. [CrossRef]

34. Edwardson, C.L.; Yates, T.; Biddle, S.J.H.; Davies, M.J.; Dunstan, D.W.; Esliger, D.W.; Gray, L.J.; Jackson, B.; O'Connell, S.E.; Waheed, G.; et al. Effectiveness of the Stand More AT (SMArT) Work intervention: Cluster randomised controlled trial. BMJ 2018, 363, k3870. [CrossRef]

35. Edwardson, C.L.; Winkler, E.A.H.; Bodicoat, D.H.; Yates, T.; Davies, M.J.; Dunstan, D.W.; Healy, G.N. Considerations when using the activPAL monitor in field-based research with adult populations. J. Sport Heal. Sci. 2017, 6, 162-178. [CrossRef] [PubMed]

36. Marshall, S.J.; Levy, S.S.; Tudor-Locke, C.E.; Kolkhorst, F.W.; Wooten, K.M.; Ji, M.; Macera, C.A.; Ainsworth, B.E. Translating Physical Activity Recommendations into a Pedometer-Based Step Goal. Am. J. Prev. Med. 2009, 36, 410-415. [CrossRef] [PubMed]

37. NHANES-National Health and Nutrition Examination Survey Homepage. Available online: https: //www.cdc.gov/nchs/nhanes/index.htm (accessed on 24 May 2019). 
38. Fairclough, S.J.; Noonan, R.; Rowlands, A.V.; Van Hees, V.; Knowles, Z.; Boddy, L.M. Wear Compliance and Activity in Children Wearing Wrist- and Hip-Mounted Accelerometers. Med. Sci. Sports Exerc. 2016, 3, 245-253. [CrossRef] [PubMed]

39. Scott, J.J.; Rowlands, A.V.; Cliff, D.P.; Morgan, P.J.; Plotnikoff, R.C.; Lubans, D.R. Comparability and feasibility of wrist- and hip-worn accelerometers in free-living adolescents. J. Sci. Med. Sport 2017, 20, 1101-1106. [CrossRef] [PubMed]

40. Clevenger, K.A.; Pfeiffer, K.A.; Mackintosh, K.A.; McNarry, M.A.; Brønd, J.; Arvidsson, D.; Montoye, A.H.K. Effect of sampling rate on acceleration and counts of hip- and wrist-worn ActiGraph accelerometers in children. Physiol. Meas. 2019, 40, 095008. [CrossRef]

41. Chandler, J.L.; Brazendale, K.; Beets, M.W.; Mealing, B.A. Classification of physical activity intensities using a wrist-worn accelerometer in 8-12-year-old children. Pediatr. Obes. 2016, 11, 120-127. [CrossRef]

42. Choi, L.; Liu, Z.; Matthews, C.E.; Buchowski, M.S. Validation of accelerometer wear and nonwear time classification algorithm. Med. Sci. Sports Exerc. 2011, 43, 357-364. [CrossRef]

43. Chau, J.Y.; Daley, M.; Srinivasan, A.; Dunn, S.; Bauman, A.E.; van der Ploeg, H.P. Desk-based workers' perspectives on using sit-stand workstations: A qualitative analysis of the Stand@Work study. BMC Public Health 2014, 14, 752. [CrossRef]

44. Pearce, M.; Page, A.S.; Griffin, T.P.; Cooper, A.R. Who children spend time with after school: Associations with objectively recorded indoor and outdoor physical activity. Int J Behav Nutr Phys Act 2014, 11, 45. [CrossRef]

45. Hnatiuk, J.A.; Hesketh, K.R.; van Sluijs, E.M.F. Correlates of home and neighbourhood-based physical activity in UK 3-4-year-old children. Eur. J. Public Health 2016, 26, 947-953. [CrossRef]

46. Lohman, T.; Roche, A.; Martorell, R. Anthropometric Standardization Reference Manual; Human Kinetics Books: Champaign, IL, USA, 1988

47. De Onis, M.; Onyango, A.W.; Borghi, E.; Siyam, A.; Nishida, C.; Siekmann, J. Development of a WHO growth reference for school-aged children and adolescents. Bull. World Health Organ. 2007, 85, 660-667. [CrossRef] [PubMed]

48. Ordnance Survey AddressBase Premium | Business and Government. Available online: http:// www.ordnancesurvey.co.uk/business-and-government/products/addressbase-premium.html (accessed on 29 October 2019).

49. Ordnance Survey OS MasterMap Topography Layer. Available online: https://www.ordnancesurvey.co.uk/ business-and-government/products/topography-layer.html (accessed on 29 October 2019).

50. Ordnance Survey MasterMap Greenspace Layer. Available online: https:/www.ordnancesurvey.co.uk/ business-and-government/products/os-mastermap-greenspace.html (accessed on 29 October 2019).

51. Noble, M.; Wright, G.; Smith, G.; Dibben, C. Measuring multiple deprivation at the small-area level. Environ. Plan. A 2006, 38, 169-185. [CrossRef]

52. Time and Date AS. Sunrise and Sunset Calculator. Available online: https://www.timeanddate.com/sun/ (accessed on 29 October 2019).

53. Roberts, J.D.; Rodkey, L.; Ray, R.; Knight, B.; Saelens, B.E. Electronic media time and sedentary behaviors in children: Findings from the Built Environment and Active Play Study in the Washington DC area. Prev. Med. Rep. 2017, 6, 149-156. [CrossRef] [PubMed]

54. Hosmer, D.W.; Lemeshow, S.; May, S. Applied Survival Analysis: Regression Modeling of Time-To-Event Data; Wiley-Interscience: Hoboken, NJ, USA, 2008; ISBN 9780471754992.

55. Kwak, S.K.; Kim, J.H. Statistical data preparation: Management of missing values and outliers. Korean J. Anesthesiol. 2017, 70, 407-411. [CrossRef] [PubMed]

56. Tabachnick, B.G.; Fidell, L.S. Using Multivariate Statistics; Harper \& Row: New York, NY, USA, 2019; ISBN 978-0-13-479054-1.

57. Dowling, R. Accommodating Open Plan: Children, Clutter, and Containment in Suburban Houses in Sydney, Australia. Environ. Plan. A Econ. Sp. 2008, 40, 536-549. [CrossRef]

58. Arundell, L.; Hinkley, T.; Veitch, J.; Salmon, J. Contribution of the after-school period to children's daily participation in physical activity and sedentary behaviours. PLoS ONE 2015, 10, 1-11. [CrossRef]

59. Cabanas-Sánchez, V.; Izquierdo-Gómez, R.; García-Cervantes, L.; Castro-Piñero, J.; Conde-Caveda, J.; Veiga, O.L. Environmental correlates of total and domain-specific sedentary behaviour in young people. The UP\&DOWN study. Eur. J. Sport Sci. 2019, 19, 696-706. 
60. Bafna, S.; Chambers, E. The influence of spatial organization of the home on inhabitant activity. A/Z ITU J. Fac. Archit. 2014, 11, 31-46.

61. Miendlarzewska, E.A.; Trost, W.J. How musical training affects cognitive development: Rhythm, reward and other modulating variables. Front. Neurosci. 2013, 7, 279. [CrossRef]

62. Rosenberg, D.E.; Sallis, J.F.; Kerr, J.; Maher, J.; Norman, G.J.; Durant, N.; Harris, S.K.; Saelens, B.E. Brief scales to assess physical activity and sedentary equipment in the home. Int. J. Behav. Nutr. Phys. Act. 2010, 7, 10. [CrossRef]

63. Atkin, A.J.; Corder, K.; van Sluijs, E.M.F. Bedroom media, sedentary time and screen-time in children: A longitudinal analysis. Int. J. Behav. Nutr. Phys. Act. 2013, 10, 137. [CrossRef] [PubMed]

64. Chaput, J.-P.; Leduc, G.; Boyer, C.; Bélanger, P.; LeBlanc, A.G.; Borghese, M.M.; Tremblay, M.S. Electronic screens in children's bedrooms and adiposity, physical activity and sleep: Do the number and type of electronic devices matter? Can. J. Public Health 2014, 105, e273-e279. [CrossRef] [PubMed]

65. Dumuid, D.; Olds, T.S.; Lewis, L.K.; Maher, C. Does home equipment contribute to socioeconomic gradients in Australian children's physical activity, sedentary time and screen time? BMC Public Health 2016, 16, 1-8. [CrossRef] [PubMed]

66. Byrom, B.; Stratton, G.; Mc Carthy, M.; Muehlhausen, W. Objective measurement of sedentary behaviour using accelerometers. Int. J. Obes. 2016, 40, 1809-1812. [CrossRef] [PubMed]

67. Harrington, D.M.; Gillison, F.; Broyles, S.T.; Chaput, J.-P.; Fogelholm, M.; Hu, G.; Kuriyan, R.; Kurpad, A.; LeBlanc, A.G.; Maher, C.; et al. Household-level correlates of children's physical activity levels in and across 12 countries. Obesity 2016, 24, 2150-2157. [CrossRef]

68. O'Connor, T.M.; Chen, T.-A.; Baranowski, J.; Thompson, D.; Baranowski, T. Physical Activity and Screen-Media-Related Parenting Practices Have Different Associations with Children's Objectively Measured Physical Activity. Child. Obes. 2013, 9, 446-453. [CrossRef]

69. Hardy, L.L.; Baur, L.A.; Garnett, S.P.; Crawford, D.; Campbell, K.J.; Shrewsbury, V.A.; Cowell, C.T.; Salmon, J. Family and home correlates of television viewing in 12-13 year old adolescents: The Nepean Study. Int. J. Behav. Nutr. Phys. Act. 2006, 9, 1-9.

70. De Decker, E.; De Craemer, M.; De Bourdeaudhuij, I.; Wijndaele, K.; Duvinage, K.; Koletzko, B.; Grammatikaki, E.; Iotova, V.; Usheva, N.; Fernández-Alvira, J.M.; et al. Influencing factors of screen time in preschool children: An exploration of parents' perceptions through focus groups in six European countries. Obes. Rev. 2012, 13, 75-84. [CrossRef]

71. Saunders, T.J.; Tremblay, M.S.; Mathieu, M.-È.; Henderson, M.; O'Loughlin, J.; Tremblay, A.; Chaput, J.-P.; Quality Cohort Research Group. Associations of Sedentary Behavior, Sedentary Bouts and Breaks in Sedentary Time with Cardiometabolic Risk in Children with a Family History of Obesity. PLoS ONE 2013, 8, e79143. [CrossRef]

72. Belcher, B.R.; Berrigan, D.; Papachristopoulou, A.; Brady, S.M.; Bernstein, S.B.; Brychta, R.J.; Hattenbach, J.D.; Tigner, I.L.; Courville, A.B.; Drinkard, B.E.; et al. Effects of Interrupting Children's Sedentary Behaviors With Activity on Metabolic Function: A Randomized Trial. J. Clin. Endocrinol. Metab. 2015, 100, 3735-3743. [CrossRef]

73. Hegarty, L.M.; Mair, J.L.; Kirby, K.; Murtagh, E.; Murphy, M.H. School-based Interventions to Reduce Sedentary Behaviour in Children: A Systematic Review. AIMS public Heal. 2016, 3, 520-541. [CrossRef] [PubMed]

74. Doherty, A.R.; Kelly, P.; Kerr, J.; Marshall, S.; Oliver, M.; Badland, H.; Hamilton, A.; Foster, C. Using wearable cameras to categorise type and context of accelerometer-identified episodes of physical activity. Int. J. Behav. Nutr. Phys. Act. 2013, 10, 22. [CrossRef] [PubMed]

75. Everson, B.; Mackintosh, K.A.; McNarry, M.A.; Todd, C.; Stratton, G.; Everson, B.; Mackintosh, K.A.; McNarry, M.A.; Todd, C.; Stratton, G. Can Wearable Cameras be Used to Validate School-Aged Children's Lifestyle Behaviours? Children 2019, 6, 20. [CrossRef] [PubMed]

76. Loveday, A.; Sherar, L.B.; Sanders, J.P.; Sanderson, P.W.; Esliger, D.W. Technologies that assess the location of physical activity and sedentary behavior: A systematic review. J. Med. Internet Res. 2015, 17, e192. [CrossRef] [PubMed]

77. Clark, B.K.; Winkler, E.A.; Brakenridge, C.L.; Trost, S.G.; Healy, G.N. Using Bluetooth proximity sensing to determine where office workers spend time at work. PLoS ONE 2018, 13, e0193971. [CrossRef] [PubMed] 
78. Loveday, A.; Sherar, L.B.; Sanders, J.P.; Sanderson, P.W.; Esliger, D.W. Novel technology to help understand the context of physical activity and sedentary behaviour. Physiol. Meas. 2016, 37, 1834-1851. [CrossRef]

79. Ding, D.; Gebel, K. Built environment, physical activity, and obesity: What have we learned from reviewing the literature? Heal. Place 2012, 18, 100-105. [CrossRef]

80. Ding, D.; Sallis, J.F.; Kerr, J.; Lee, S.; Rosenberg, D.E. Neighborhood environment and physical activity among youth a review. Am. J. Prev. Med. 2011, 41, 442-455. [CrossRef]

81. Neshteruk, C.D.; Mazzucca, S.; Østbye, T.; Ward, D.S. The physical environment in family childcare homes and children's physical activity. Child. Care. Health Dev. 2018, 44, 746-752. [CrossRef]

82. Brazendale, K.; Beets, M.W.; Turner-McGrievy, G.M.; Kaczynski, A.T.; Pate, R.R.; Weaver, R.G. Children's Obesogenic Behaviors During Summer Versus School: A Within-Person Comparison. J. Sch. Health 2018, 88, 886-892. [CrossRef]

(C) 2019 by the authors. Licensee MDPI, Basel, Switzerland. This article is an open access article distributed under the terms and conditions of the Creative Commons Attribution (CC BY) license (http://creativecommons.org/licenses/by/4.0/). 